\title{
Sensorless Rotor-Field Oriented Controlled Induction Motor Drive with Particle Swarm Optimization Algorithm Speed Controller Design Strategy
}

\author{
Yung-Chang Luo, Zhi-Sheng Ke, and Ying-Piao Kuo \\ Department of Electrical Engineering, National Chin-Yi University of Technology, No. 57, Section 2, Zhongshan Road, \\ Taiping District, Taichung 41170, Taiwan
}

Correspondence should be addressed to Yung-Chang Luo; luoyc@ncut.edu.tw

Received 26 February 2014; Accepted 16 April 2014; Published 12 June 2014

Academic Editor: Her-Terng Yau

Copyright (c) 2014 Yung-Chang Luo et al. This is an open access article distributed under the Creative Commons Attribution License, which permits unrestricted use, distribution, and reproduction in any medium, provided the original work is properly cited.

\begin{abstract}
A sensorless rotor-field oriented control induction motor drive with particle swarm optimization algorithm speed controller design strategy is presented. First, the rotor-field oriented control scheme of induction motor is established. Then, the current-and-voltage serial-model rotor-flux estimator is developed to identify synchronous speed for coordinate transformation. Third, the rotor-shaft speed on-line estimation is established applying the model reference adaptive system method based on estimated rotor-flux. Fourth, the speed controller of sensorless induction motor drive is designed using particle swarm optimization algorithm. Simulation and experimental results confirm the effectiveness of the proposed approach.
\end{abstract}

\section{Introduction}

Automatic production facilities require numerous motors to actuate mechanical load. Direct current (DC) motors demand frequent maintenance requirements and are unsuitable for dirty and explosive environments because of the presence of brushes and commutators. Induction motors (IM) possess lower volume and weight, are more reliable and efficient, and require fewer maintenance requirements. However, the control of an IM drive is more complicated than a DC motor drive. Since Blaschke presented the field oriented control (FOC) theory of an IM [1], it is through suitable coordinate transformation that the nonlinear, coupling, and time-varying model of IM can be converted as a DC separately excited motor, which field and armature voltage can be independently controlled, and DC like drive performance can be achieved. Nevertheless, the implementation of FOC requires rotor-shaft encoder to detect rotor-shaft position. This position sensor, however, reduces the drive reliability and is unsuitable for hostile environment. Hence, the sensorless FOC approaches, which utilize flux linkage and speed estimation methods, have been extensively used to replace the conventional FOC IM drives $[2,3]$.
Model reference adaptive system (MRAS) method has been applied to estimate rotor-shaft speed for speed sensorless IM drive [4], which has a number of advantages, including easy implementation, simple structure, and lower parameters sensitivity.

Particle swarm optimization (PSO) algorithm is one of the optimum control approaches which possesses rapid convergence and lesser adjusting parameters and which is suitable for dynamic conditions application [5]. Hence, the speed controller design procedure is developed based on PSO algorithm for sensorless rotor FOC IM drive in this paper.

\section{Rotor-Field Oriented Control Induction Motor Drive}

The stator and rotor voltage state equations of IM in the synchronous reference coordinate frame are [6]

$$
\begin{aligned}
& \vec{v}_{s}=R_{s} \vec{i}_{s}+j \omega_{e} \vec{\lambda}_{s}+p \vec{\lambda}_{s}, \\
& 0=R_{r} \vec{i}_{r}+j \omega_{s l} \vec{\lambda}_{r}+p \vec{\lambda}_{r},
\end{aligned}
$$


where $\vec{v}_{s}=v_{d s}+j v_{q s}$ is the stator voltage, $\vec{i}_{s}=i_{d s}+j i_{q s}$ is the stator current, $\vec{\lambda}_{s}=\lambda_{d s}+j \lambda_{q s}$ is the stator flux linkage, $\vec{i}_{r}=$ $i_{d r}+j i_{q r}$ is the rotor current, $\vec{\lambda}_{r}=\lambda_{d r}+j \lambda_{q r}$ is the rotor-flux linkage, $R_{s}$ is the stator resistance, $R_{r}$ is the rotor resistance, $\omega_{e}$ is the speed of the synchronous reference coordinate frame, $\omega_{s l}=\omega_{e}-\omega_{r}$ is the slip speed, $\omega_{r}$ is the electric speed of the rotor, and $p=d / d t$ is the differential operator. The stator and rotor-flux linkage are given by

$$
\begin{aligned}
& \vec{\lambda}_{s}=L_{s} \vec{i}_{s}+L_{m} \vec{i}_{r}, \\
& \vec{\lambda}_{r}=L_{r} \vec{i}_{r}+L_{m} \vec{i}_{s},
\end{aligned}
$$

where $L_{s}$ is the stator inductance, $L_{r}$ is the rotor inductance, and $L_{m}$ is the mutual inductance.

The developed electromagnetic torque of IM can be obtained by

$$
T_{e}=\frac{3 P}{4} L_{m}\left(i_{q s} i_{d r}-i_{d s} i_{q r}\right)
$$

where $P$ is the pole number of the motor. The mechanical equation of the motor is

$$
J_{m} p \omega_{r m}+B_{m} \omega_{r m}+T_{L}=T_{e},
$$

where $J_{m}$ is the inertia of the motor, $B_{m}$ is the viscous friction coefficient, $T_{L}$ is the load torque, and $\omega_{r m}$ is the mechanical speed of the motor rotor-shaft. The speed of the motor rotorshaft can also be expressed as

$$
\omega_{r m}=\frac{2}{P} \omega_{r}
$$

Under the rotor-field oriented control (RFOC) condition, set $\lambda_{q r}=0$ in (2) and (4); the estimated slip speed can be derived as

$$
\widehat{\omega}_{s l}=\frac{L_{m} i_{q s}}{\tau_{r} \lambda_{d r}},
$$

where $\tau_{r}=L_{r} / R_{r}$ is the rotor time constant, and the rotor flux linkage is obtained by

$$
\lambda_{d r}=\frac{L_{m} i_{d s}}{1+\tau_{r} s}
$$

where $s$ is the Laplace operator. The developed electromagnetic torque of IM under RFOC condition can be derived as

$$
T_{e}=\frac{3 P}{4} \frac{L_{m}}{L_{r}} \lambda_{d r} i_{q s}
$$

Hence, the dynamic equations of IM under RFOC can be expressed as

$$
\begin{aligned}
& p\left[\begin{array}{c}
i_{d s} \\
i_{q s} \\
\lambda_{d r}
\end{array}\right] \\
& =\left[\begin{array}{ccc}
-\frac{R_{s}}{\sigma L_{s}}-\frac{1-\sigma}{\sigma \tau_{r}} & \omega_{e} & \frac{1-\sigma}{\sigma L_{m} \tau_{r}} \\
-\omega_{e} & -\frac{R_{s}}{\sigma L_{s}} & -\frac{(1-\sigma) \omega_{e}}{\sigma L_{m}} \\
\frac{L_{m}}{\tau_{r}} & 0 & -\frac{1}{\tau_{r}}
\end{array}\right]\left[\begin{array}{c}
i_{d s} \\
i_{q s} \\
\lambda_{d r}
\end{array}\right] \\
& +\frac{1}{\sigma L_{s}}\left[\begin{array}{c}
v_{d s} \\
v_{q s} \\
0
\end{array}\right],
\end{aligned}
$$

where $\sigma=1-L_{m}^{2} /\left(L_{s} L_{r}\right)$.

Examining (11) as nonlinear and coupling differential equations, the linear control can be acquired by utilizing feedforward voltage compensation skill. The linear output signal of the $q$-axis stator current control loop can be expressed as

$$
v_{q s}^{\prime}=\left(K_{p q}+\frac{K_{i q}}{s}\right)\left(i_{q s}^{*}-i_{q s}\right),
$$

where $i_{q s}^{*}$ is the command of the $q$-axis stator current and $K_{p q}$ and $K_{i q}$ are the proportion and integral gain parameter of the $q$-axis stator current controller, respectively.

The second row of (11) through the decoupling procedure can be expressed as

$$
p i_{q s}=-\frac{R_{s}}{\sigma L_{s}} i_{q s}+v_{q s}^{\prime} .
$$

Comparing (13) with the second row of (11), the decoupling control of the $q$-axis stator current control loop can be obtained by defining the feedforward voltage compensation as

$$
\sigma L_{s}\left(\omega_{e} i_{d s}+\frac{1-\sigma}{\sigma L_{m}} \omega_{e} \hat{\lambda}_{d r}\right)
$$

where $\hat{\lambda}_{d r}$ is the estimated $d$-axis rotor-flux linkage. Consequently, the decoupling voltage equation of the $q$-axis stator current control loop is derived as

$$
v_{q s}^{*}=\sigma L_{s}\left(v_{q s}^{\prime}+\omega_{e} i_{d s}+\frac{1-\sigma}{\sigma L_{m}} \omega_{e} \widehat{\lambda}_{d r}\right),
$$

where $v_{q s}^{*}$ is the command of the $q$-axis stator voltage.

Similarly, the feedforward voltage compensation of the $d$ axis stator current control loop should be defined as

$$
\sigma L_{s}\left(-\omega_{e} i_{q s}-\frac{1-\sigma}{\sigma \tau_{r} L_{m}} \hat{\lambda}_{d r}\right) .
$$




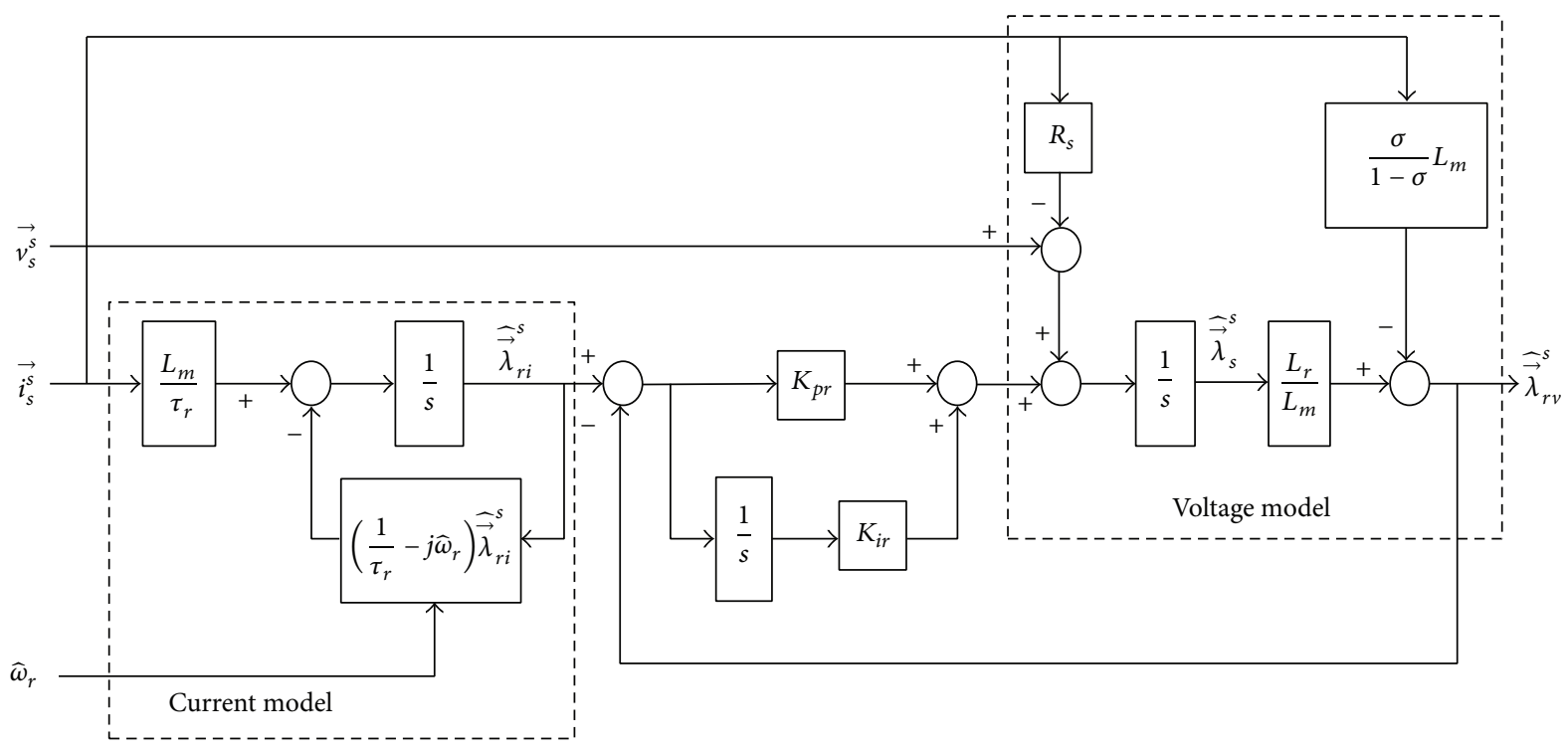

FIGURE 1: Current-and-voltage serial-model rotor-flux estimator.

Then the decoupling control of the $d$-axis stator current control loop can be acquired, and the decoupling voltage equation of the $d$-axis stator current control loop is derived as

$$
v_{d s}^{*}=\sigma L_{s}\left(v_{d s}^{\prime}-\omega_{e} i_{q s}-\frac{1-\sigma}{\sigma \tau_{r} L_{m}} \lambda_{d r}\right),
$$

where $v_{d s}^{*}$ is the command of the $d$-axis stator voltage and $v_{d s}^{\prime}$ is the linear output signal of the $d$-axis stator current control loop.

\section{Sensorless RFOC Induction Motor Drive}

It is necessary to design a speed estimator to replace the feedback speed in the sensorless RFOC induction motor drive, and the speed estimator can be acquired from the rotorflux estimator.

3.1. Rotor-Flux Estimator. The stator current and rotor-flux linkage are chosen as state variables in RFOC scheme. Rewrite (4) as

$$
\vec{i}_{r}=\frac{1}{L_{r}}\left(\vec{\lambda}_{r}-L_{m} \vec{i}_{s}\right) .
$$

Then, substituting (18) into (3), the stator flux linkage can be expressed as the function of stator current and rotor-flux linkage; that is,

$$
\vec{\lambda}_{s}=\sigma L_{s} \vec{i}_{s}+\frac{L_{m}}{L_{r}} \vec{\lambda}_{r} .
$$

Substituting (19) into (1), the stator voltage equation can be also expressed by

$$
\vec{v}_{s}=\left(R_{s}+j \omega_{e} \sigma L_{s}+\sigma L_{s} p\right) \vec{i}_{s}+\frac{L_{m}}{L_{r}}\left(j \omega_{e}+p\right) \vec{\lambda}_{r} .
$$

Set $\omega_{e}=0$ in (20); the voltage-model rotor-flux estimator can be derived as

$$
p \widehat{\vec{\lambda}}_{r v}^{s}=\frac{L_{r}}{L_{m}}\left[\vec{v}_{s}^{s}-\left(R_{s}+\sigma L_{s} p\right) \vec{i}_{s}^{s}\right],
$$

where the superscript " $s$ " is represented in the stationary coordinate frame.

Then, substituting (18) into (2) and setting also $\omega_{e}=0$, the current-model rotor-flux estimator can be derived as

$$
p \widehat{\vec{\lambda}}_{r i}^{s}=\frac{L_{m}}{\tau_{r}} \vec{i}_{s}^{s}-\left(\frac{1}{\tau_{r}}-j \omega_{r}\right) \widehat{\vec{\lambda}}_{r i}^{s} .
$$

Both voltage-model and current-model rotor-flux estimators are open loop estimators. The current-model flux estimator is affected by the rotor resistance variation at low speeds, which is affected by the rotor resistance and mutual inductance variation at high speeds. The voltage-model flux estimator is affected by the stator resistance variation and the magnitude of stator voltage at low speeds but is less affected by the parameters variation at high speeds. Hence, the currentmodel rotor-flux estimator is applied for low speeds and the voltage-model rotor-flux estimator is suitable for high speeds [6]. In this paper, the closed loop type current-and-voltage serial-model rotor-flux estimator is proposed to improve the estimated rotor-flux for entire speeds and that is shown in Figure 1.

Applying the estimated $d$-axis rotor-flux linkage $\widehat{\lambda}_{d r}^{s}$ and estimated $q$-axis rotor-flux linkage $\widehat{\lambda}_{q r}^{s}$, which are acquired from Figure 1, the synchronous angular speed for coordinate transformation between the stationary reference frame and synchronous reference frame can be obtained; that is,

$$
\widehat{\theta}_{e}=\tan ^{-1}\left(\frac{\hat{\lambda}_{q r}^{s}}{\hat{\lambda}_{d r}^{s}}\right) .
$$




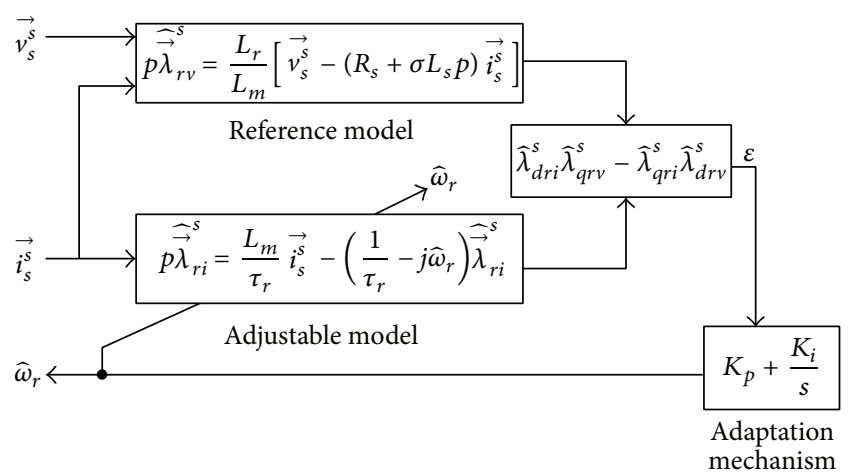

FIGURE 2: MRAS rotor speed estimator based on estimated rotorflux linkage.

3.2. MRAS Rotor Speed On-Line Estimated Scheme. The estimated synchronous angular speed $\widehat{\omega}_{e}$ is derived from the current-and-voltage serial-model rotor-flux estimator, and the estimated rotor speed $\widehat{\omega}_{r}$ can be obtained by subtracting slip speed $\widehat{\omega}_{s l}$ from $\widehat{\omega}_{e}$.

According to MRAS speed estimated scheme, which is proposed by Schauder [7], the on-line MRAS estimated rotor electrical speed is shown in Figure 2. The voltage-model rotor-flux estimator relying on (21) is chosen as the reference model, and the current-model rotor-flux estimator relying on (22) is chosen as the adjustable model; then the error between the reference model and the adjustable model can be expressed as (24), where the error is passed through an adaptation mechanism to estimate the rotor electrical speed in Figure 2. Consider

$$
\varepsilon=\widehat{\lambda}_{d r i}^{s} \widehat{\lambda}_{q r v}^{s}-\widehat{\lambda}_{q r i}^{s} \widehat{\lambda}_{d r v}^{s}
$$

3.3. PSO Speed Controller Design Strategy. PSO is originally proposed by Kennedy and Eberhart [5, 8], which is devised to simulate social behavior. The iterative method is applied in PSO to improve candidate solution (called particles) to acquire prescribed measure of quality. These particles are moved around in the search-space according to their position and velocity. Each particle possesses individual optimum searching variable to correct searching direction in the search-space and that is called particle cognition-only model. Comparing individual optimum searching variable with swarm searching variables and then updating swarm searching variables, to correct searching velocity of the particles, is called swarm social-only model. Hence, the acquired optimum solution of a problem is according to the best adaptation value in PSO.

Conventional PSO algorithm has a disadvantage of local solution rapid convergence. Consequently, some modified PSO algorithms are presented, which include inertia weight method, tracking dynamic system method, and constriction factors method [9]. The inertia weight method is applied in this paper, which provides PSO with the ability to search rapidly for optimum solution at initial stage, and possesses

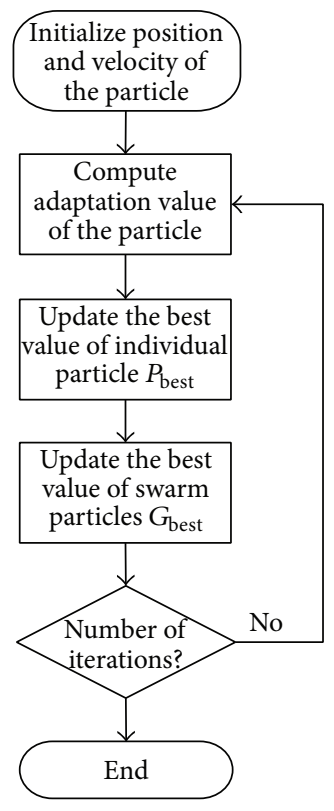

FIGURE 3: The flowchart of PSO algorithm.

effective convergence at later stage; the position and velocity updated formulae are described as follows:

$$
\begin{gathered}
V_{i}(k+1)=w \times V_{i}(k)+C_{1} \times \text { Rand } \times\left(P_{\text {best }}-x_{i}\right) \\
+C_{2} \times \text { Rand } \times\left(G_{\text {best }}-x_{i}\right), \\
x_{i}(k+1)=x_{i}(k)+V_{i}(k+1),
\end{gathered}
$$

where $V_{i}(k)$ and $x_{i}(k)$ are the velocity and position of the particle, respectively, $P_{\text {best }}$ and $G_{\text {best }}$ are the optimum solution position of the individual particle and swarm particles, respectively, $w$ is the weighting factor, $C_{1}$ and $C_{2}$ are the learning factors, and Rand is the uniform distribution random variable over $[0,1]$.

The flowchart of PSO algorithm is shown in Figure 3.

The first particle is produced randomly and the best function value can be found by iteration searching in PSO algorithm. The best solution is obtained by applying $P_{\text {best }}$ and $G_{\text {best }}$ to compute optimum variable. The design procedure of PSO algorithms is as follows.

Step 1. Create initial position and velocity of the particle in $d$-dimension space randomly.

Step 2. Apply objective function to compute the adaptation value of each particle.

Step 3. Compare the position of the present particle with the searching best solution position $P_{\text {best }}$ of individual particle. If the new searching adaptation value of the present particle is better to $P_{\text {best }}$, then update $P_{\text {best }}$ with the new searching adaptation value of the present particle.

Step 4. Compare the position of the present particle with the searching best solution position $G_{\text {best }}$ of swarm particles. If 


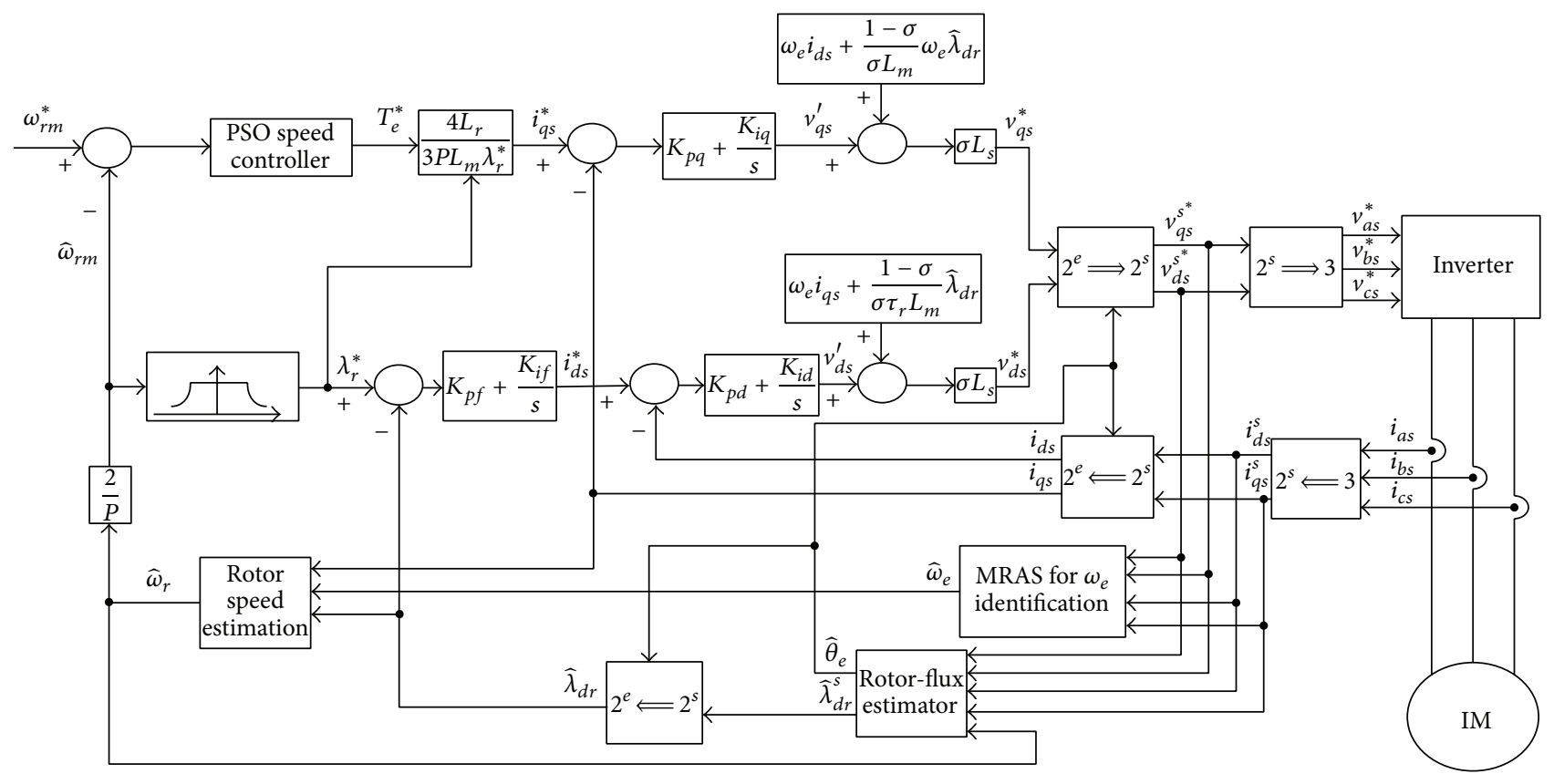

FIGURE 4: Sensorless RFOC IM drive with PSO algorithm speed controller design.

the new searching adaptation value of the present particle is better to $G_{\text {best }}$, then update $G_{\text {best }}$ with the new searching adaptation value of the present particle.

Step 5. Utilizing (25), update the position and velocity of the particle.

Step 6. Repeat Step 2 Step 5 until the desired accuracy is obtained.

\section{Simulation and Experimental}

The block diagram of the proposed sensorless RFOC IM drive with PSO algorithm speed controller is shown in Figure 4, which includes PSO algorithm speed controller, flux controller, $q$-axis and $d$-axis stator current controllers, voltage decouple, coordinate transformation, MRAS based rotor speed estimator, and current-and-voltage serial-model rotor-flux estimator. In this system, the speed control loop is designed using PSO algorithm, the flux control loop, $d$ axis and $q$-axis stator current control loops are designed proportion-integral (PI) type controller based on the rootlocus method. The Bode plot of the proposed speed control loop based on PSO design is shown in Figure 5. The proportion gain $\left(K_{p}\right)$, integral gain $\left(K_{i}\right)$, and bandwidth $(B . W)$ for four controllers are shown in Table 1. The simulation scheme that was designed utilizing toolbox Matlab \Simulink is shown in Figure 6.

To confirm the effectiveness of the proposed sensorless RFOC IM drive with PSO algorithm speed controller design,

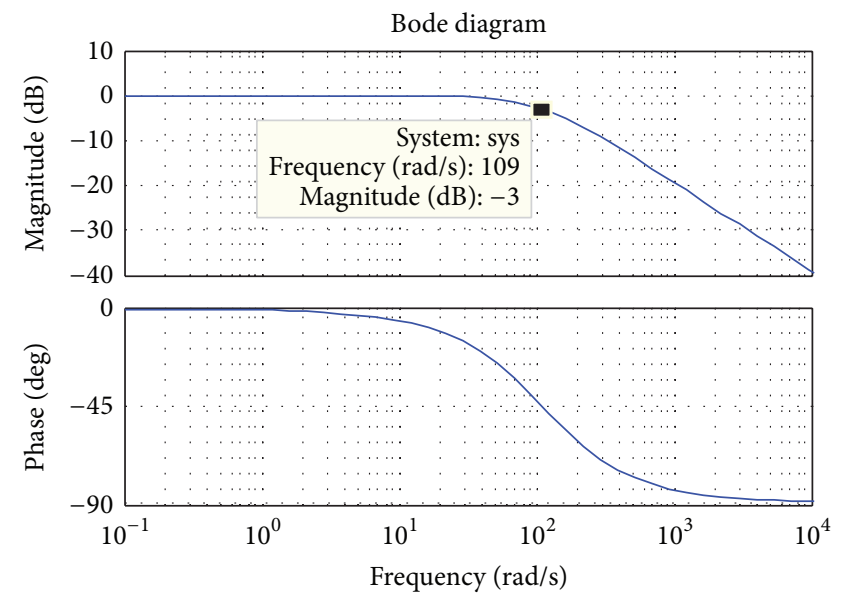

FIGURE 5: Bode plot of the speed control loop based on PSO design.

TABLE 1: Controller parameters and its bandwidth.

\begin{tabular}{lccc}
\hline & $K_{p}$ & $K_{i}$ & $B . W$ \\
\hline Speed controller & 0.9898 & 1.4847 & 109 \\
Flux controller & 486.55 & 90.15 & 1060 \\
$q$-axis stator current controller & 616.51 & 410.99 & 2970 \\
$d$-axis stator current controller & 895.49 & 447.84 & 3970 \\
\hline
\end{tabular}

a 3-phase, $220 \mathrm{~V}, 0.75 \mathrm{~kW}, \Delta$-connected, standard squirrelcage IM (the parameters of the used IM are listed in Table 2) 


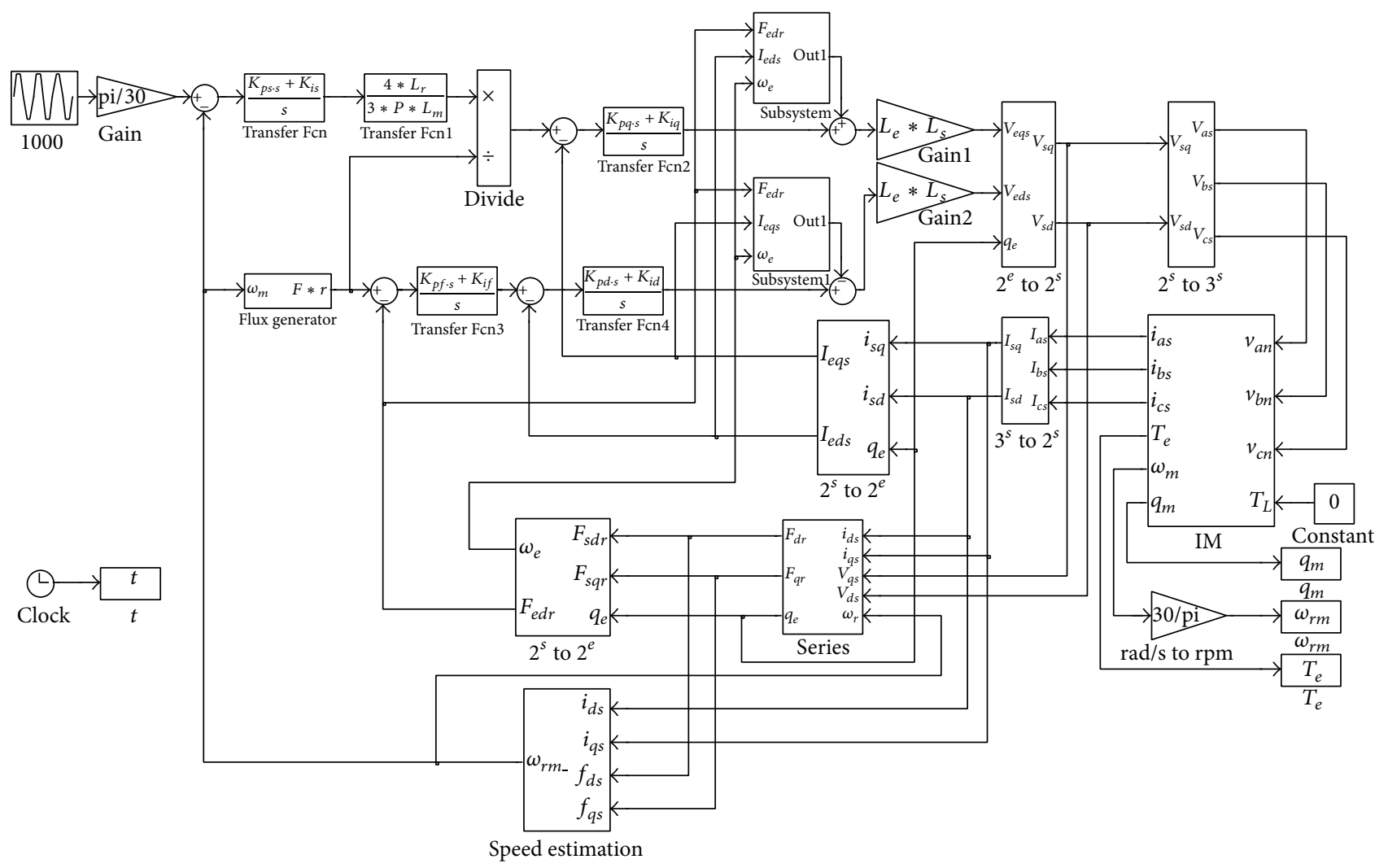

FIGURE 6: Simulation scheme for sensorless RFOC IM drive with PSO algorithm speed controller design.

TABLE 2: The parameters of the used IM

\begin{tabular}{lc}
\hline Poles & 4 \\
$R_{s}(\Omega)$ & 2.85 \\
$R_{r}(\Omega)$ & 2.3433 \\
$L_{s}(\mathrm{H})$ & 0.1967 \\
$L_{r}(\mathrm{H})$ & 0.1967 \\
$L_{m}(\mathrm{H})$ & 0.1886 \\
$J_{m}\left(\mathrm{Nt}-\mathrm{s}^{2} / \mathrm{m}\right)$ & 0.009 \\
$B_{m}\left(\mathrm{Nt}-\mathrm{s}^{2} / \mathrm{m}^{2}\right)$ & 0.00825 \\
\hline
\end{tabular}

is used, which serves as the controlled plant for experimentation. To confirm the effectiveness of the proposed sensorless RFOC IM drive with PSO algorithm speed controller design, a 3-phase, $220 \mathrm{~V}, 0.75 \mathrm{~kW}, \Delta$-connected, standard squirrelcage IM is used, which serves as the controlled plant for experimentation. In a running cycle, the speed command is designed as follows: forward direction acceleration from $t=0$ to $t=1 \mathrm{sec}$; forward direction steady-state operation during $1 \leq t \leq 2 \mathrm{sec}$; forward direction braking operation to reach zero speed in the interval $2 \leq t \leq 3 \mathrm{sec}$; reverse direction acceleration from $t=3$ to $t=4 \mathrm{sec}$; reverse direction steady-state operation during $4 \leq t \leq 5 \mathrm{sec}$; and reverse direction braking operation to reach zero speed in the interval $5 \leq t \leq 6 \mathrm{sec}$. The simulated and measured responses are shown in Figures 7-18. Each figure contains four responses: the actual shaft speed, the estimated shaft speed, the rotor-flux linkage locus, and the estimated electromagnetic torque. The simulated and measured responses with no-load for reversible steady-state speed commands $\pm 300 \mathrm{rpm}, \pm 900 \mathrm{rpm}$, and $\pm 1800 \mathrm{rpm}$ are shown in Figures $7,8,9,10,11$, and 12 , respectively. And the simulated and measured responses with loading $2 \mathrm{~N}-\mathrm{m}$ for reversible steadystate speed commands $\pm 300 \mathrm{rpm}, \pm 900 \mathrm{rpm}$, and $\pm 1800 \mathrm{rpm}$ are shown in Figures 13, 14, 15, 16, 17, and 18, respectively.

Based on the simulated and experimental results for different operational speeds as shown in Figures 7-18, the proposed MRAS rotor-shaft speed on-line estimation sensorless RFOC IM drive with PSO algorithm speed controller design strategy has shown that the desired performance can be acquired.

\section{Conclusions}

A sensorless RFOC based on current-and-voltage serialmodel rotor-flux estimator with PSO algorithm speed controller design strategy has been proposed to control an IM drive. The proposed rotor-flux estimator acquired exactly estimation flux angle position of coordinate transformation between the synchronous reference coordinate frame and the stationary reference coordinate frame. The flux 


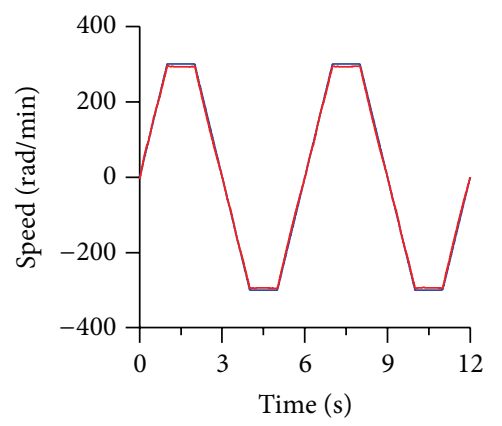

(a)

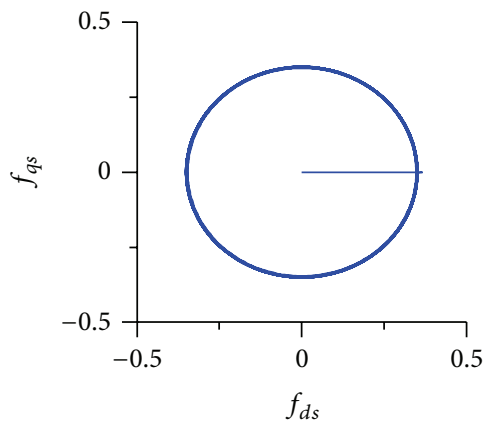

(c)

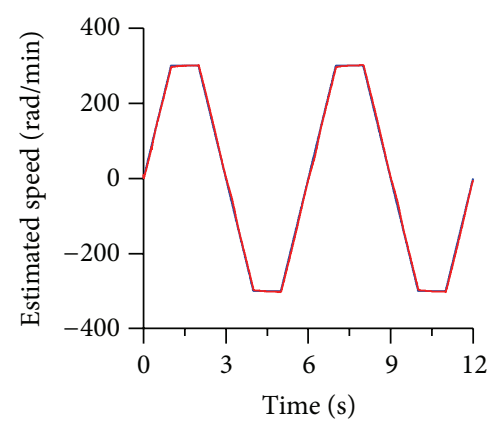

(b)

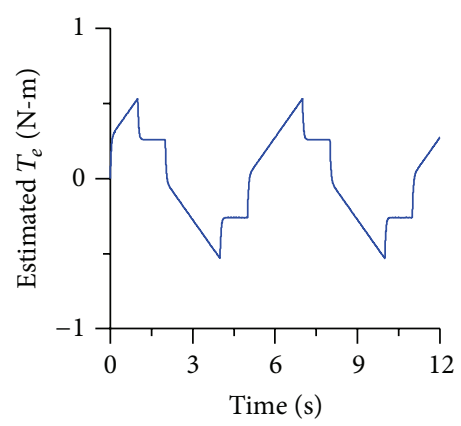

(d)

FIGURE 7: Simulated responses of MRAS sensorless RFOC IM dive with PSO algorithm speed controller design strategy with no-load at reversible steady-state speed command $300 \mathrm{rpm}$. (a) Command speed (blue line) and actual shaft speed (red line), (b) command speed (blue line) and estimated shaft speed (red line), (c) rotor flux linkage locus, (d) estimated electromagnetic torque.

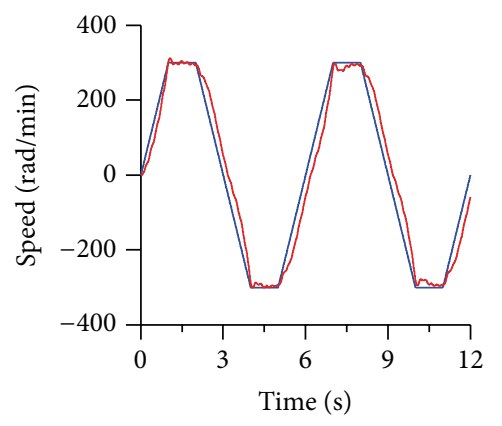

(a)

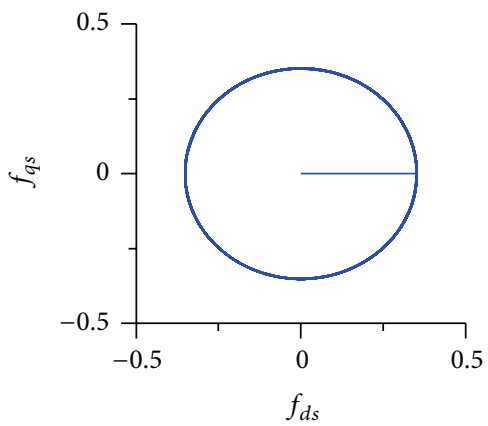

(c)

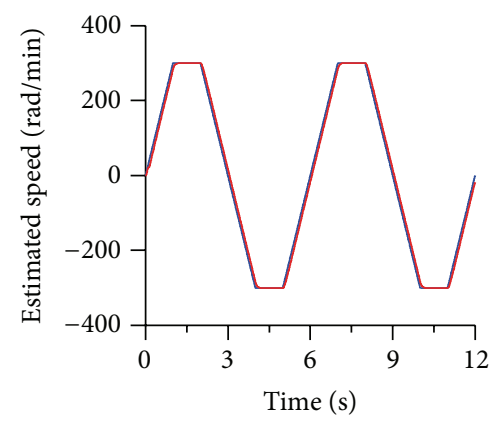

(b)

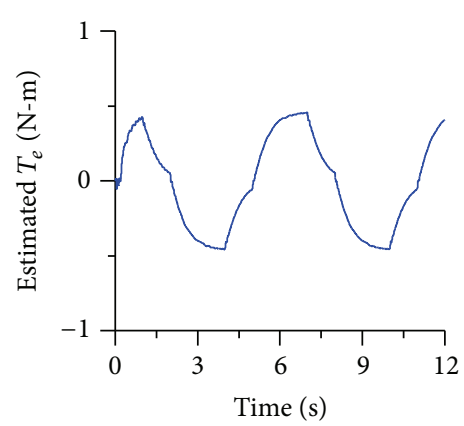

(d)

FIGURE 8: Measured responses of MRAS sensorless RFOC IM dive with PSO algorithm speed controller design strategy with no-load at reversible steady-state speed command $300 \mathrm{rpm}$. (a) Command speed (blue line) and actual shaft speed (red line), (b) command speed (blue line) and estimated shaft speed (red line), (c) rotor flux linkage locus, (d) estimated electromagnetic torque. 


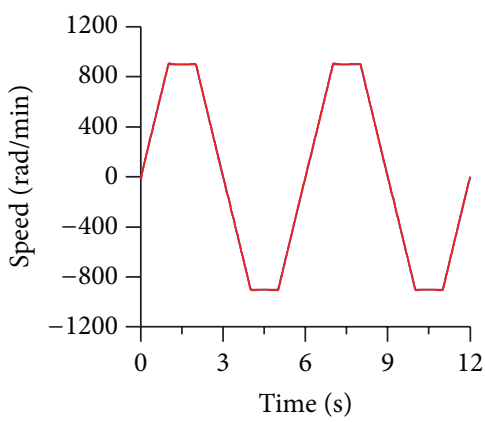

(a)

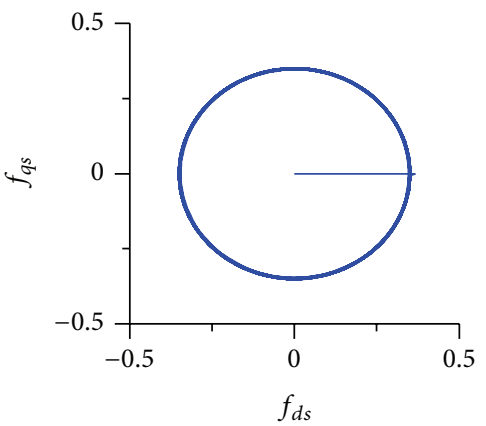

(c)

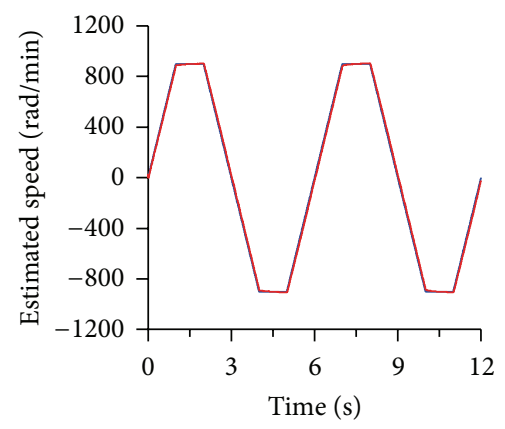

(b)

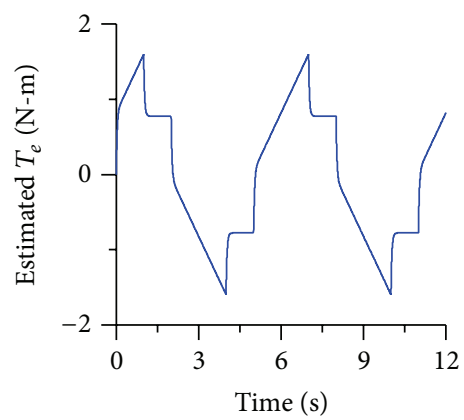

(d)

FIGURE 9: Simulated responses of MRAS sensorless RFOC IM dive with PSO algorithm speed controller design strategy with no-load at reversible steady-state speed command $900 \mathrm{rpm}$. (a) Command speed (blue line) and actual shaft speed (red line), (b) command speed (blue line) and estimated shaft speed (red line), (c) rotor flux linkage locus, (d) estimated electromagnetic torque.

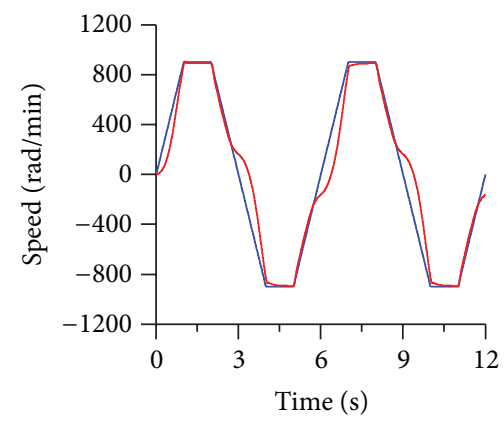

(a)

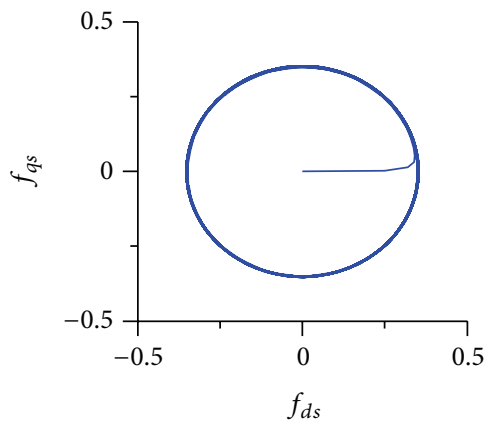

(c)

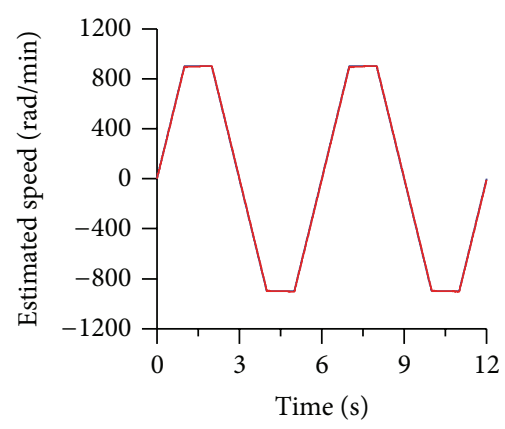

(b)

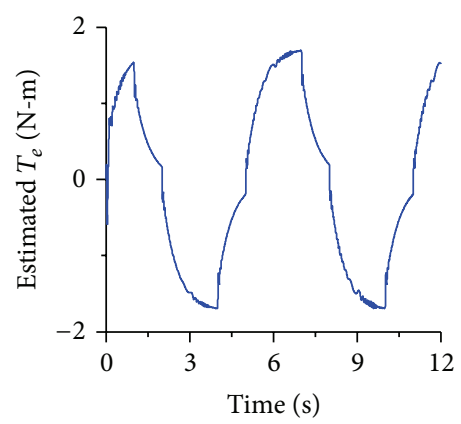

(d)

FIGURE 10: Measured responses of MRAS sensorless RFOC IM dive with PSO algorithm speed controller design strategy with no-load at reversible steady-state speed command $900 \mathrm{rpm}$. (a) Command speed (blue line) and actual shaft speed (red line), (b) command speed (blue line) and estimated shaft speed (red line), (c) rotor flux linkage locus, (d) estimated electromagnetic torque. 


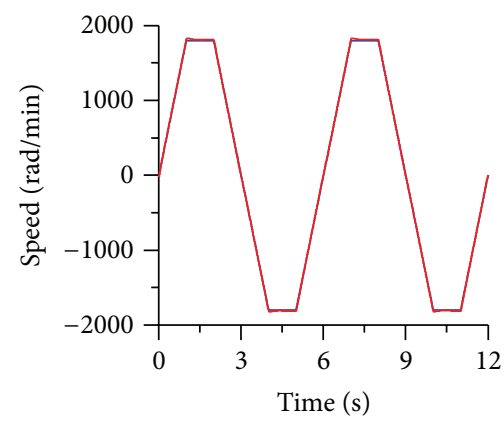

(a)

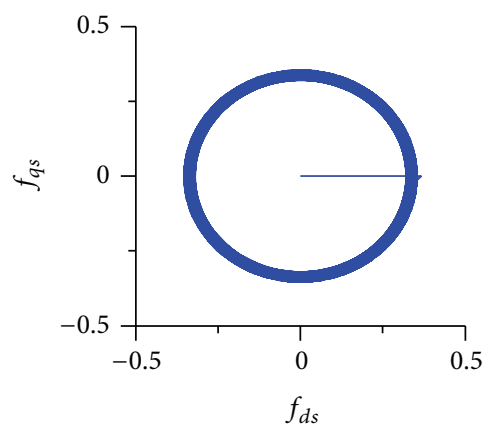

(c)

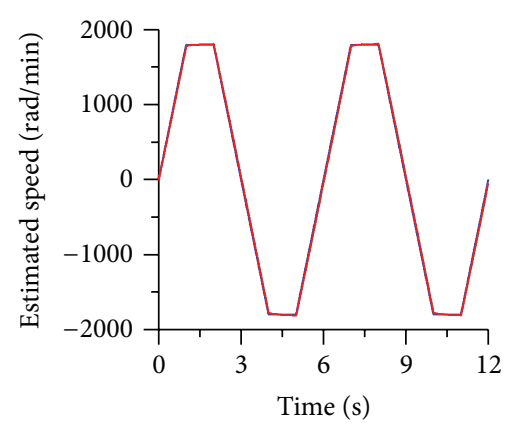

(b)

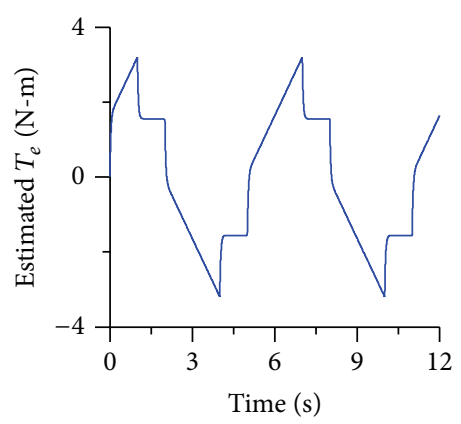

(d)

FIGURE 11: Simulated responses of MRAS sensorless RFOC IM dive with PSO algorithm speed controller design strategy with no-load at reversible steady-state speed command $1800 \mathrm{rpm}$. (a) Command speed (blue line) and actual shaft speed (red line), (b) command speed (blue line) and estimated shaft speed (red line), (c) rotor flux linkage locus, (d) estimated electromagnetic torque.

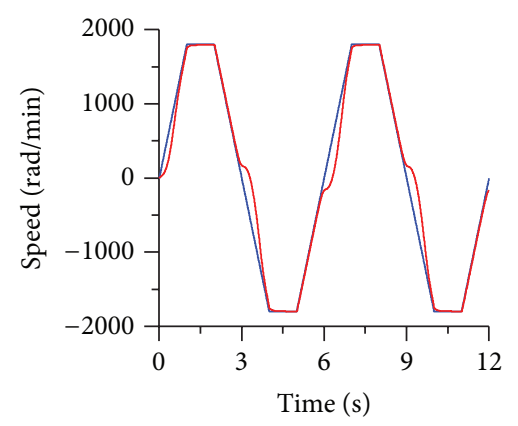

(a)

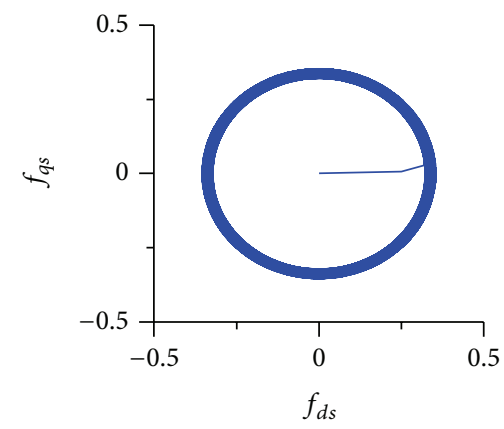

(c)

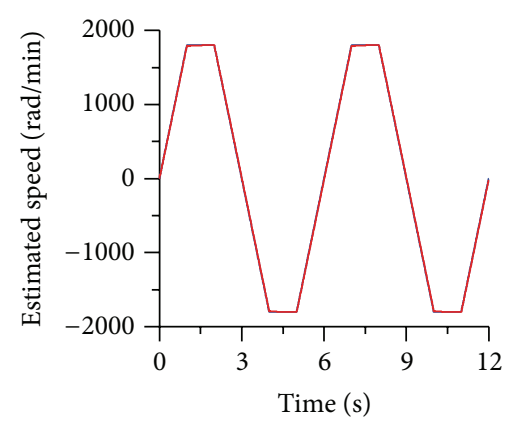

(b)

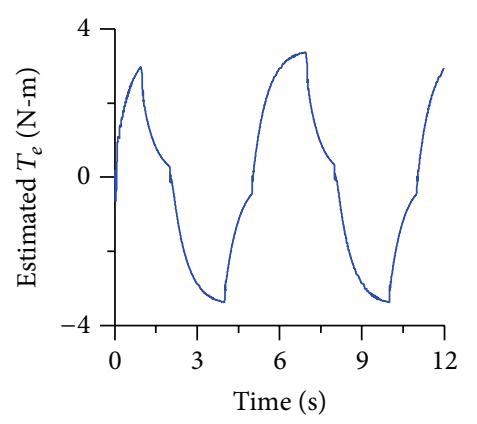

(d)

FIGURE 12: Measured responses of MRAS sensorless RFOC IM dive with PSO algorithm speed controller design strategy with no-load at reversible steady-state speed command $1800 \mathrm{rpm}$. (a) Command speed (blue line) and actual shaft speed (red line), (b) command speed (blue line) and estimated shaft speed (red line), (c) rotor flux linkage locus, (d) estimated electromagnetic torque. 


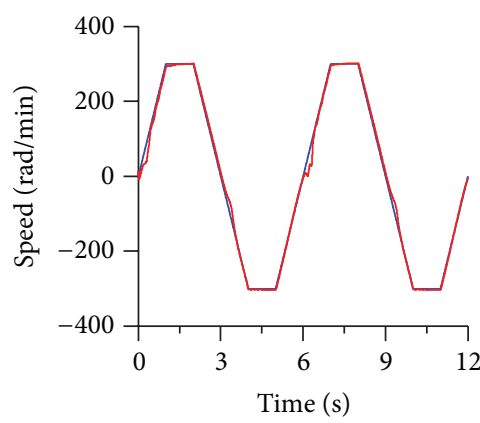

(a)

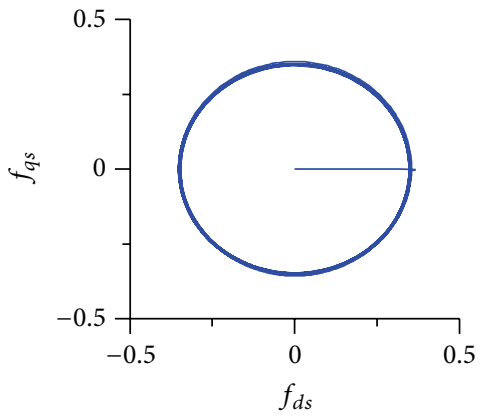

(c)

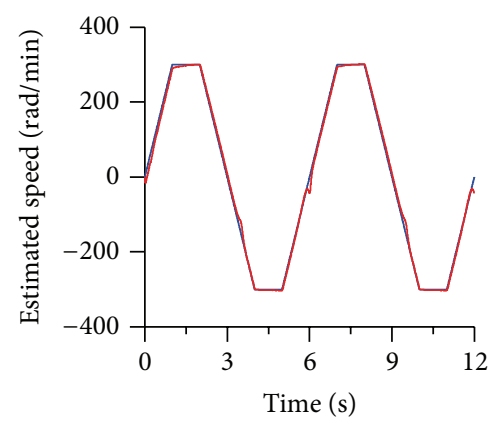

(b)

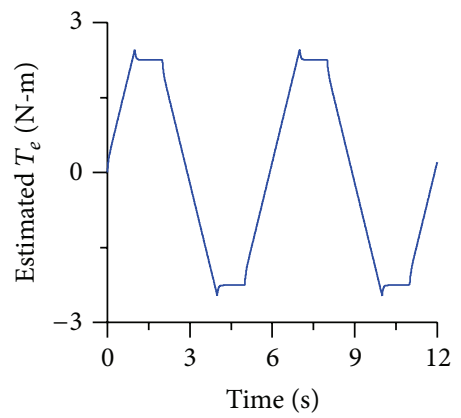

(d)

FIGURE 13: Simulated responses of MRAS sensorless RFOC IM dive with PSO algorithm speed controller design strategy with loading $2 \mathrm{~N}$-m at reversible steady-state speed command $300 \mathrm{rpm}$. (a) Command speed (blue line) and actual shaft speed (red line), (b) command speed (blue line) and estimated shaft speed (red line), (c) rotor flux linkage locus, (d) estimated electromagnetic torque.

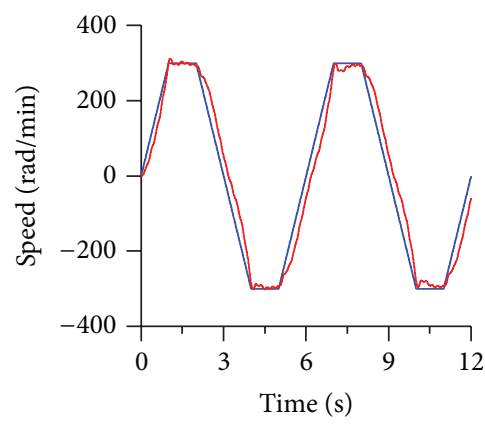

(a)

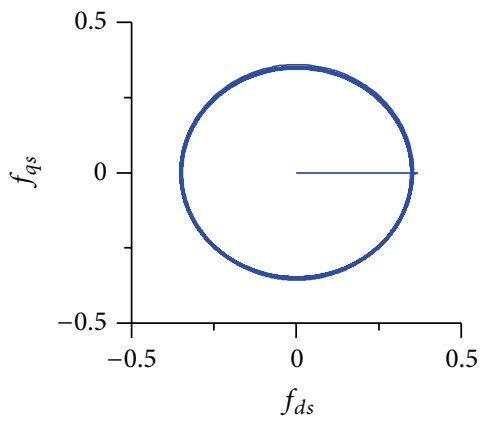

(c)

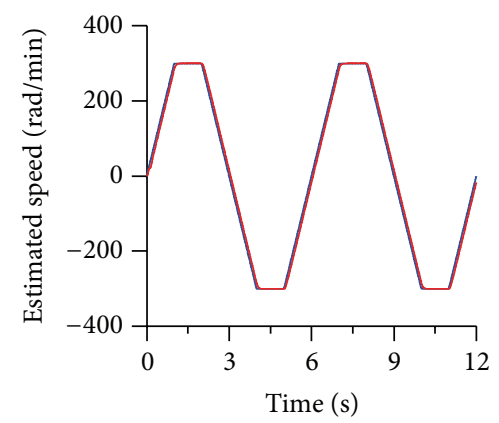

(b)

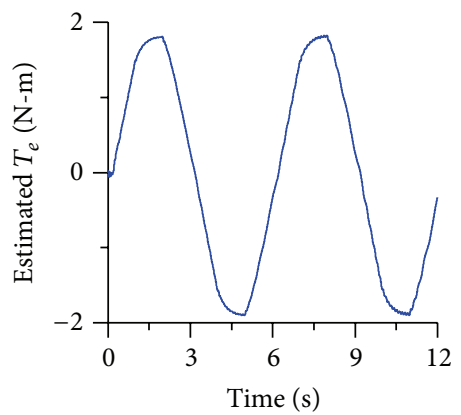

(d)

FIGURE 14: Measured responses of MRAS sensorless RFOC IM dive with PSO algorithm speed controller design strategy with loading 2 N-m at reversible steady-state speed command $300 \mathrm{rpm}$. (a) Command speed (blue line) and actual shaft speed (red line), (b) command speed (blue line) and estimated shaft speed (red line), (c) rotor flux linkage locus, (d) estimated electromagnetic torque. 


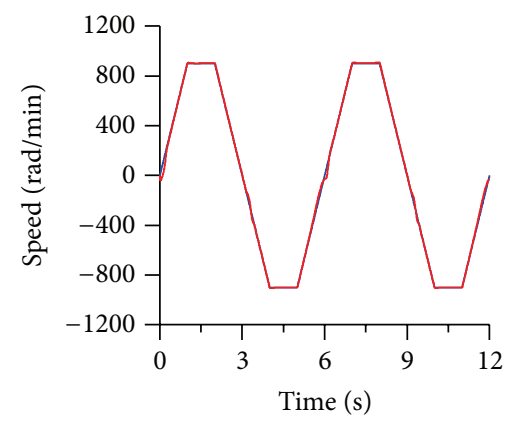

(a)

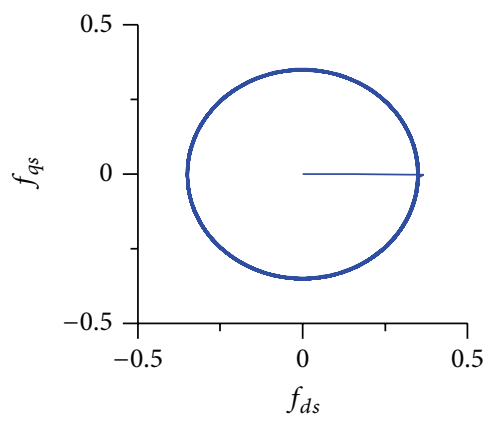

(c)

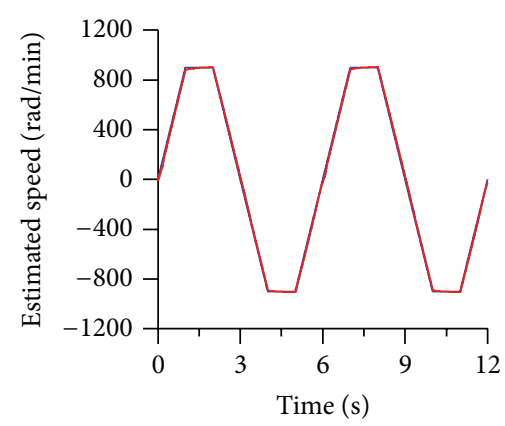

(b)

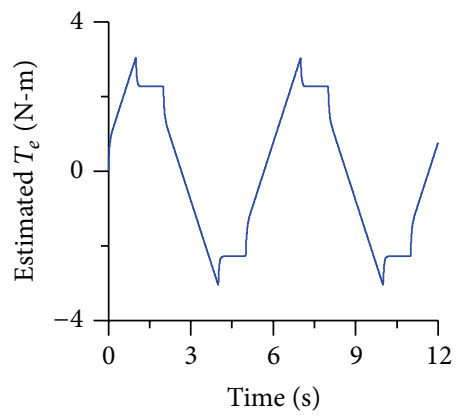

(d)

FIGURE 15: Simulated responses of MRAS sensorless RFOC IM dive with PSO algorithm speed controller design strategy with loading $2 \mathrm{~N}-\mathrm{m}$ at reversible steady-state speed command $900 \mathrm{rpm}$. (a) Command speed (blue line) and actual shaft speed (red line), (b) command speed (blue line) and estimated shaft speed (red line), (c) rotor flux linkage locus, (d) estimated electromagnetic torque.

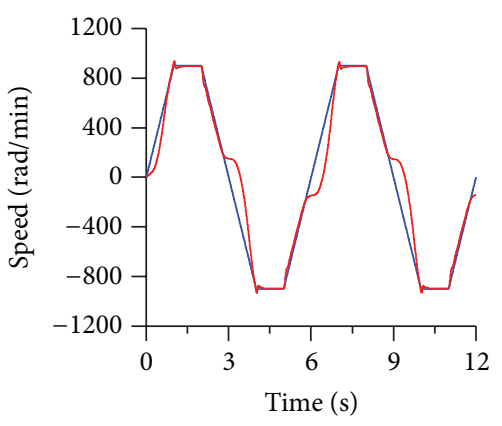

(a)

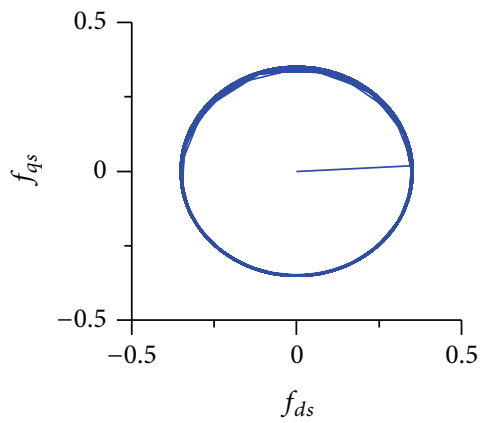

(c)

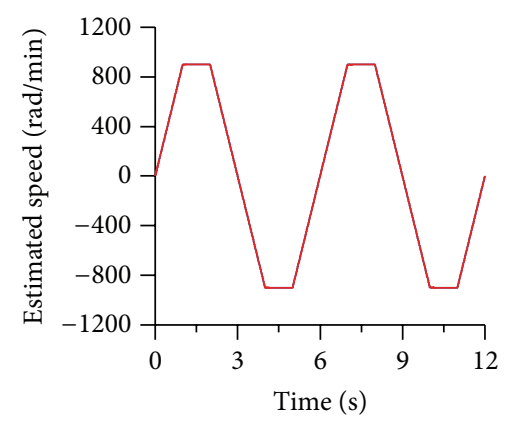

(b)

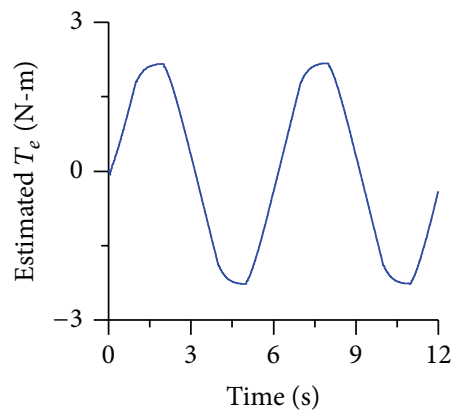

(d)

FIGURE 16: Measured responses of MRAS sensorless RFOC IM dive with PSO algorithm speed controller design strategy with loading $2 \mathrm{~N}-\mathrm{m}$ at reversible steady-state speed command $900 \mathrm{rpm}$. (a) Command speed (blue line) and actual shaft speed (red line), (b) command speed (blue line) and estimated shaft speed (red line), (c) rotor flux linkage locus, (d) estimated electromagnetic torque. 


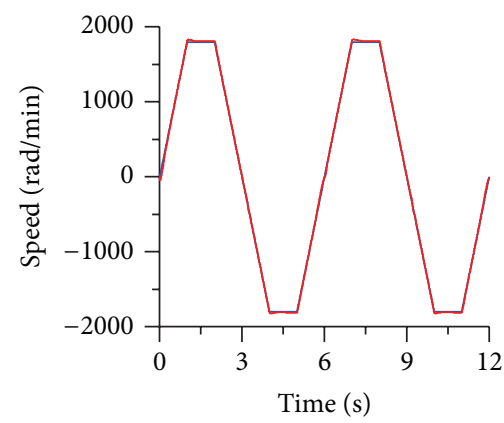

(a)

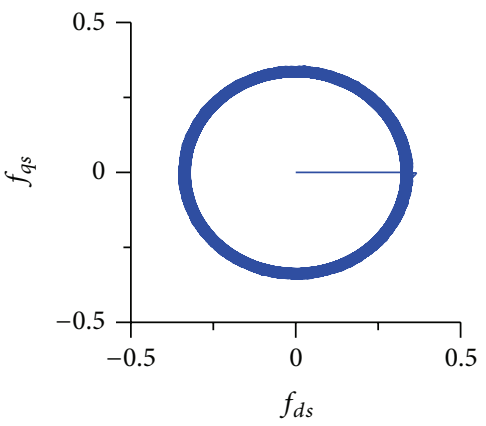

(c)

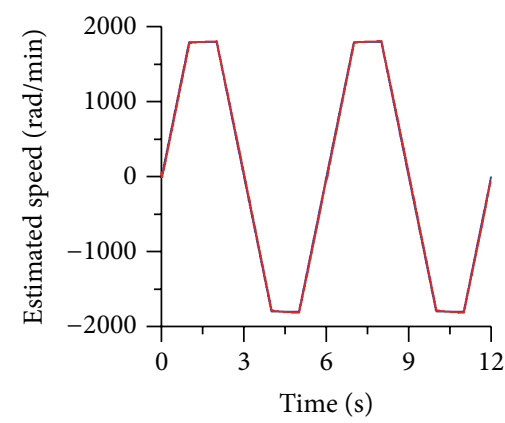

(b)

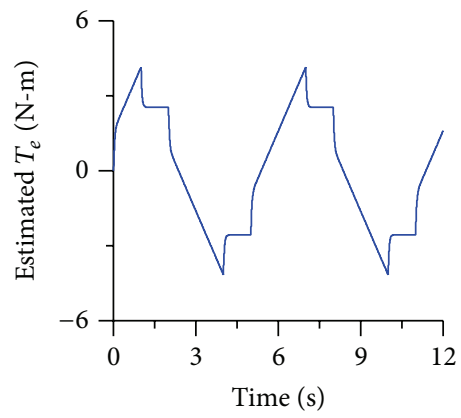

(d)

FIGURE 17: Simulated responses of MRAS sensorless RFOC IM dive with PSO algorithm speed controller design strategy with loading $2 \mathrm{~N}$-m at reversible steady-state speed command $1800 \mathrm{rpm}$. (a) Command speed (blue line) and actual shaft speed (red line), (b) command speed (blue line) and estimated shaft speed (red line), (c) rotor flux linkage locus, (d) estimated electromagnetic torque.

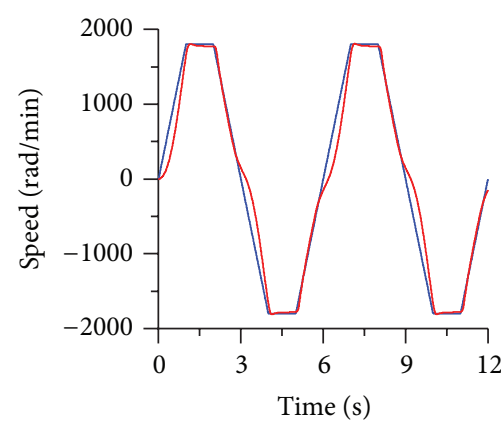

(a)

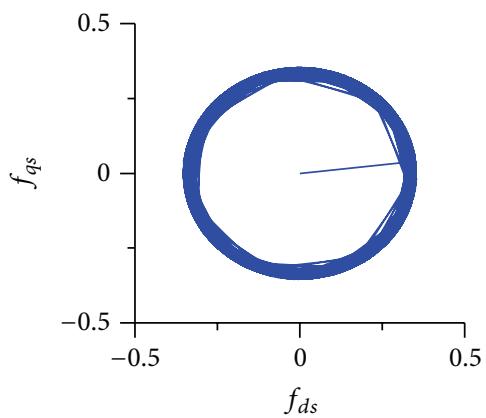

(c)

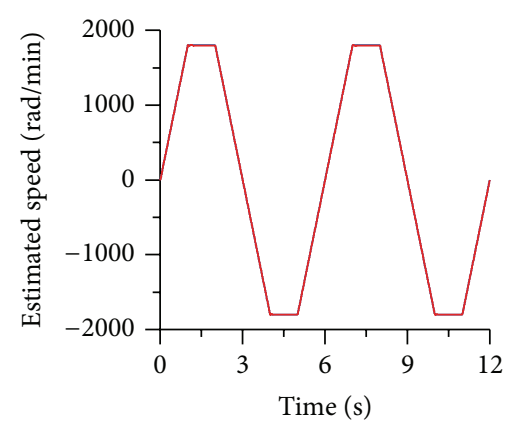

(b)

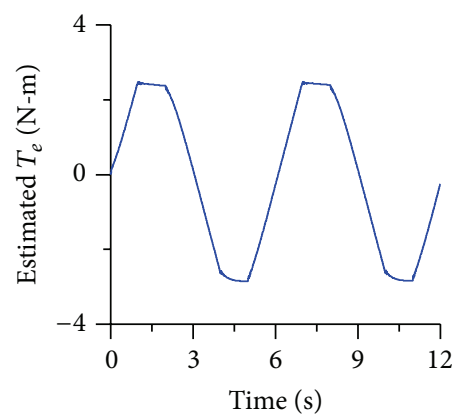

(d)

FIGURE 18: Measured responses of MRAS sensorless RFOC IM dive with PSO algorithm speed controller design strategy with loading $2 \mathrm{~N}-\mathrm{m}$ at reversible steady-state speed command $1800 \mathrm{rpm}$. (a) Command speed (blue line) and actual shaft speed (red line), (b) command speed (blue line) and estimated shaft speed (red line), (c) rotor flux linkage locus, (d) estimated electromagnetic torque. 
estimator based MRAS scheme can accurately identify the rotor-shaft speed on-line. The speed controller design strategy utilizing PSO algorithm obtained superior speed response. The simulated and experimental responses at different reversible steady-state speed commands $( \pm 300 \mathrm{rpm}$, $\pm 900 \mathrm{rpm}$, and $\pm 1800 \mathrm{rpm}$ ) confirm the effectiveness of the proposed approach.

\section{Conflict of Interests}

The authors declare that there is no conflict of interests regarding the publication of this paper.

\section{References}

[1] F. Blaschke, "The principle of field orientation as applied to the new transvektor closed-loop control system for rotating-field machines," Siemens Review, vol. 39, no. 5, pp. 217-220, 1972.

[2] H. Tajima and Y. Hori, "Speed sensorless field-orientation control of the induction machine," IEEE Transactions on Industry Applications, vol. 29, no. 1, pp. 175-180, 1993.

[3] Y. C. Luo and W. X. Chen, "Sensorless stator field orientation controlled induction motor drive with fuzzy speed controller," Computers and Mathematics with Applications, vol. 64, no. 5, pp. 1206-1216, 2012.

[4] Y. D. Landau, Adaptive Control: The Model Reference Approach, vol. 8, Marcel Dekker, New York, NY, USA, 1979.

[5] J. Kennedy and R. C. Eberhart, "Particle swarm optimization," in Proceedings of the IEEE International Conference on Neural Networks, vol. 4, pp. 1942-1948, IEEE, Perth, Australia, December 1995.

[6] C. H. Liu, Control of AC Electrical Machines, Tunghua, Taipei, Taiwan, 4th edition, 2008 (Chinese).

[7] C. Schauder, "Adaptive speed identification for vector control of induction motors without rotational transducers," IEEE Transactions on Industry Applications, vol. 28, no. 5, pp. 10541061, 1992.

[8] R. Eberhart and J. Kennedy, "A New optimizer using particle swarm theory," in Proceedings of the 6th International Symposium on Micro Machine and Human Science, pp. 39-43, IEEE, Nagoya, Japan, October 1995.

[9] Y. Shi and R. Eberhart, "Modified particle swarm optimizer," in Proceedings of the IEEE International Conference on Evolutionary Computation (ICEC '98), pp. 69-73, IEEE, Anchorage, Alaska, USA, May 1998. 


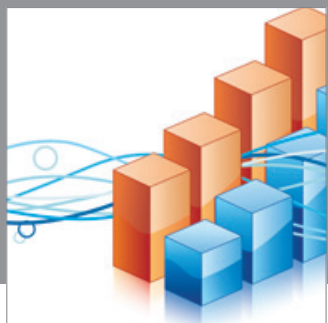

Advances in

Operations Research

mansans

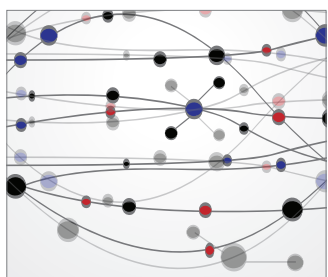

The Scientific World Journal
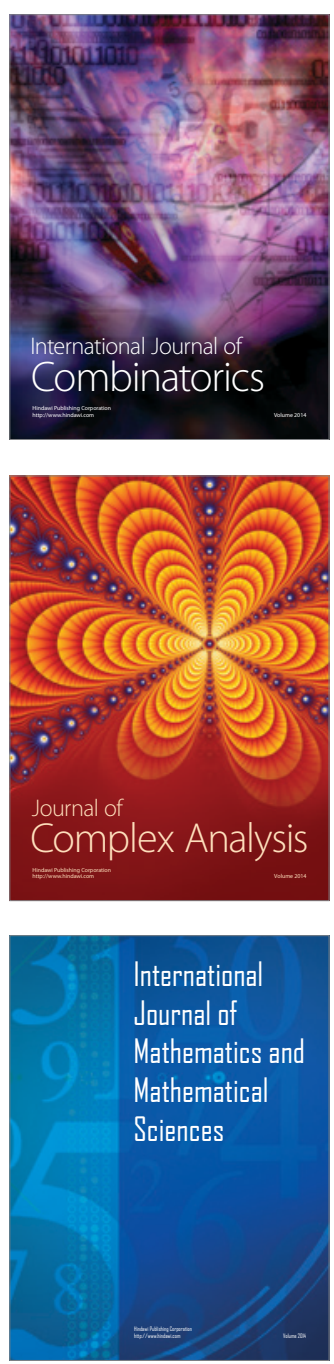
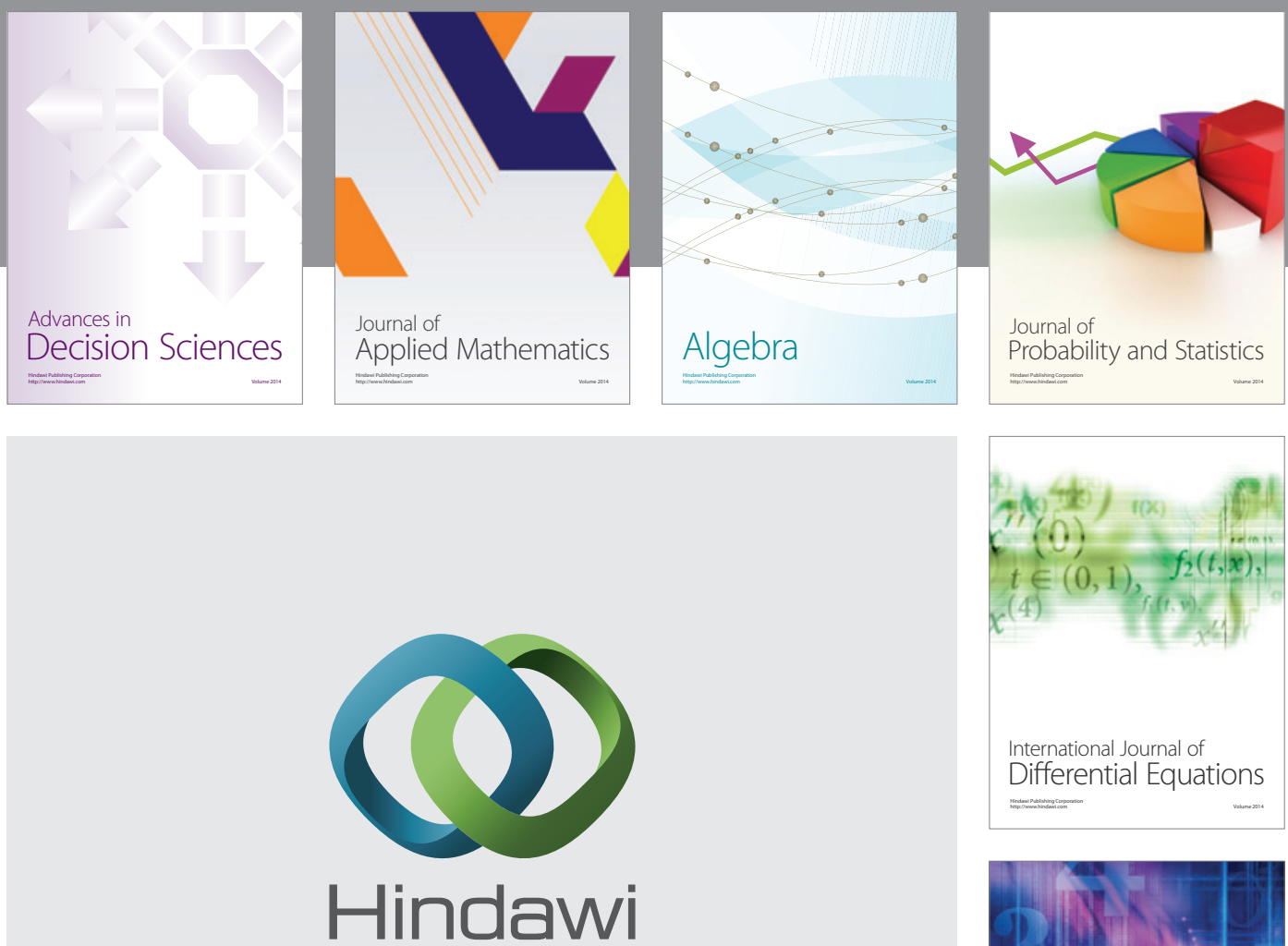

Submit your manuscripts at http://www.hindawi.com
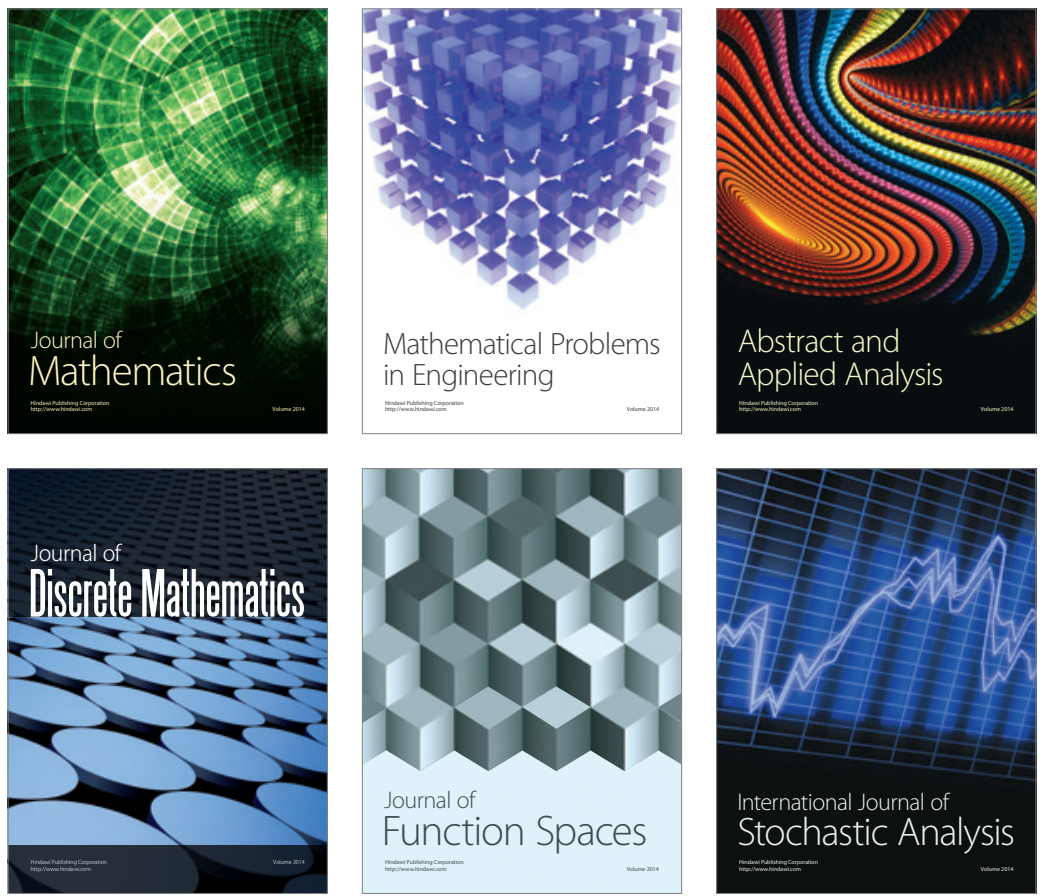

Journal of

Function Spaces

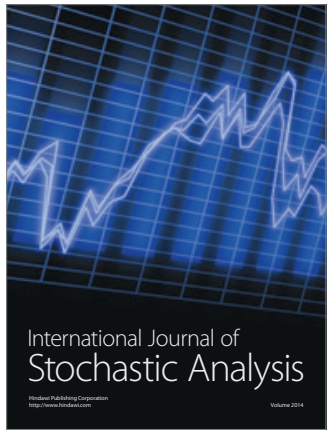

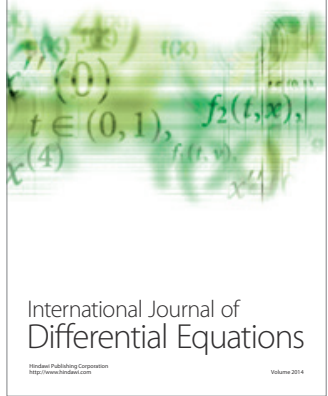
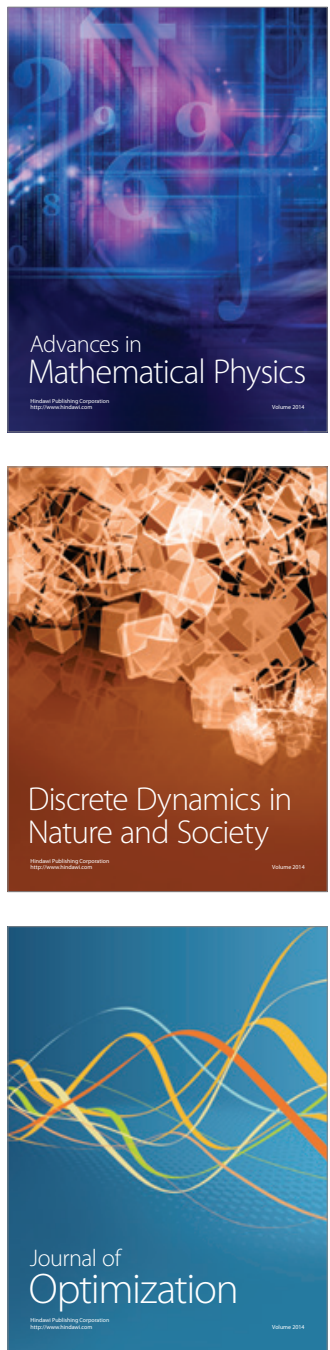